\title{
Study on Electrodeposition Process of Molybdenum Doped Vanadium Oxide Electrochromism Films
}

\author{
WANG Kun ${ }^{1, a}$, JIN Ai Ping ${ }^{1, b^{*}}$ and PENG Jun Jun ${ }^{1, c}$ \\ ${ }^{1}$ School of Chemistry and Chemical Engineering, Wuhan Textile University, Wuhan 40073, China \\ awangkun1990@sina.cn, jinaiping2000@163.com, cjohn_peng@wtu.edu.cn
}

Keywords: Electrodeposition, Molybdenum doped vanadium oxide, Film, Thickness, Electrochromism

Abstract. Molybdenum doped vanadium oxide (Mo doped $\mathrm{V}_{2} \mathrm{O}_{5}$ ) xerogel films are prepared by cathodic electrodeposition on indium tin oxide substrate from Mo doped $\mathrm{V}_{2} \mathrm{O}_{5}$ sol. As an anodic and cathodic coloration electrochromic material, the electrodeposited Mo doped $\mathrm{V}_{2} \mathrm{O}_{5}$ film presents multi-electrochromic behavior (orange-yellow-green-blue) with an optical modulation of 30-62\% in the spectral region 550-800 $\mathrm{nm}$, which can be expected as a result of different film thickness. The electrodeposited process of $\mathrm{Mo}$ doped $\mathrm{V}_{2} \mathrm{O}_{5}$ films is investigated. With the increase of the electrodeposition time, the thickness of the films increases gradually. The thickness of the films increases sharply with the increase of the concentration of the sol. When the film thickness is about $400 \mathrm{~nm}$, the optical modulation range of the film is about $60 \%$.

\section{Introduction}

The great interest on the electrochromic effect shown by transition metal oxides, such as $\mathrm{V}_{2} \mathrm{O}_{5}$ and $\mathrm{MoO}_{3}$, are due to their possible applications in smart windows, information display, light shutters, variable reflectance mirrors and variable-emittance thermal radiators [1-4]. Among electrochromic transition metal oxides, $\mathrm{V}_{2} \mathrm{O}_{5}$ shows anodic and cathodic coloration, and the electrochromism of $\mathrm{V}_{2} \mathrm{O}_{5}$-based films can be considered as a reversible reduction/oxidation process accompanying the double insertion/extraction of $\mathrm{Li}^{+}$ions and electrons [5]. Recently, we described the preparation of Mo doped $\mathrm{V}_{2} \mathrm{O}_{5}$ films by cathodic electrodeposition at various cathodic potentials from Mo doped $\mathrm{V}_{2} \mathrm{O}_{5}$ sol and studied their electrochromic mechanism [6,7]. Electrodeposited method is probably the most economical method for making the films in addition to its relative ease in forming large area films. In this article, the electrodeposited process of Mo doped $\mathrm{V}_{2} \mathrm{O}_{5}$ films was further studied. The effects of electrodeposition time and sol concentration on film thickness were investigated. Moreover, the relationship between film thickness and electrochromic properties was discussed.

\section{Experimental Procedure}

Mo doped $\mathrm{V}_{2} \mathrm{O}_{5}$ sol was formed by sol-gel combined with hydrothermal reaction. Firstly, the peroxo-polymolybdate solution was mixed with $30 \mathrm{~mL}$ of $\mathrm{V}_{2} \mathrm{O}_{5}$ sol to form a mixed sol by stirring for $1 \mathrm{~h}$, and then the sol was kept into autoclaves at $180{ }^{\circ} \mathrm{C}$ for $12 \mathrm{~h}$. The molar ratio of Mo to $\mathrm{V}_{2} \mathrm{O}_{5}$ was $5 \mathrm{~mol} \%$. Mo doped $\mathrm{V}_{2} \mathrm{O}_{5}$ sol laid motionless for two to five days before electrodeposition. By changing the concentration of $\mathrm{V}_{2} \mathrm{O}_{5}$ sol, different concentrations of Mo doped $\mathrm{V}_{2} \mathrm{O}_{5}$ sol were prepared. The concentrations of Mo doped $\mathrm{V}_{2} \mathrm{O}_{5}$ sol were $0.0125,0.025,0.050,0.075$ and $0.10 \mathrm{M}$.

Mo doped $\mathrm{V}_{2} \mathrm{O}_{5}$ films were prepared by cathodic electrodeposition [6,7]. The film electrodepositions and electrochemical experiments were carried out with an Autolab model PGSTAT30 potentiostat/galvanostat interfaced to a computer. The standard three-electrode arrangement was used. The counter electrode was a platinum sheet with an area of $1 \mathrm{~cm}^{2}$. The reference electrode was saturated calomel electrode (SCE). The ITO-coated glass substrates act as the working electrode. Mo doped $\mathrm{V}_{2} \mathrm{O}_{5}$ films were deposited potentiostatically by applying a fixed potential of $-0.3 \mathrm{~V}$ vs. SCE for different length of time (10, 30, 60, 120, 240, 600 and $1200 \mathrm{~s})$ from Mo doped $\mathrm{V}_{2} \mathrm{O}_{5}$ sol with the concentration of $0.05 \mathrm{M}$. Mo doped $\mathrm{V}_{2} \mathrm{O}_{5}$ films were also deposited 
potentiostatically by applying a fixed potential of $-0.3 \mathrm{~V}$ vs. SCE for a predetermined length of time (100s) from Mo doped $\mathrm{V}_{2} \mathrm{O}_{5}$ sol with the different concentrations $(0.0125,0.025,0.050,0.075$ and $0.10 \mathrm{M})$. Following deposition, the films were dried in air at room temperature. After heat treatment in air oven at $120^{\circ} \mathrm{C}$ for $24 \mathrm{~h}$, the homogeneous yellow films were obtained.

Film thickness was measured with the sectional view of films by scanning electron microscope (Phenom Pro). The electrochromic films were polarized in an electrolytic solution of $0.5 \mathrm{M} \mathrm{LiClO}_{4}$ (Aldrich) in propylene carbonate (PC) (Aldrich) using chronoamperometry at 1.0, 0.3, $-0.3,-0.3$ and $-1.0 \mathrm{~V}$ for $30 \mathrm{~s}$, respectively. The optical properties of Mo doped $\mathrm{V}_{2} \mathrm{O}_{5}$ films were characterized by UV-Visible spectrophotometer (TENSOR-27 model).

\section{Results and Discussion}

Effect of electrodeposition time on film thickness and electrochromic property. The maximal transmittance change $\Delta T_{\max }$ is used to indicate the ability of the optical modulator of the electrochromic materials. Fig. 1 shows the effect of electrodeposition time on film thickness and $\Delta T_{\max }$ with a specific sol concentration of $0.05 \mathrm{M}$. Fig. 3 shows the corresponding ex-situ optical transmittance data for Mo doped $\mathrm{V}_{2} \mathrm{O}_{5}$ films with different electrodeposition time $(10,120$ and $1200 \mathrm{~s})$ in different coloration states, which the film was polarized at $+1.0,+0.3,-0.3$, and $-1.0 \mathrm{~V}$, respectively. As can be seen, with the extension of the electrodeposition time (from $10 \mathrm{~s}$ to $1200 \mathrm{~s}$ ), the thickness of the films increases gradually (from about $90 \mathrm{~nm}$ to $1050 \mathrm{~nm}$ ). Moreover, $\Delta T_{\max }$ for the film with different electrodepositon time is $38-62 \%$ in the spectral region $550-800 \mathrm{~nm}$, while $\Delta T_{\max }$ reach a maximum value of $61 \%$ at the electrodeposition time of $120 \mathrm{~s}$ with the film thickness of about $400 \mathrm{~nm}$, as shown in Fig. 2.

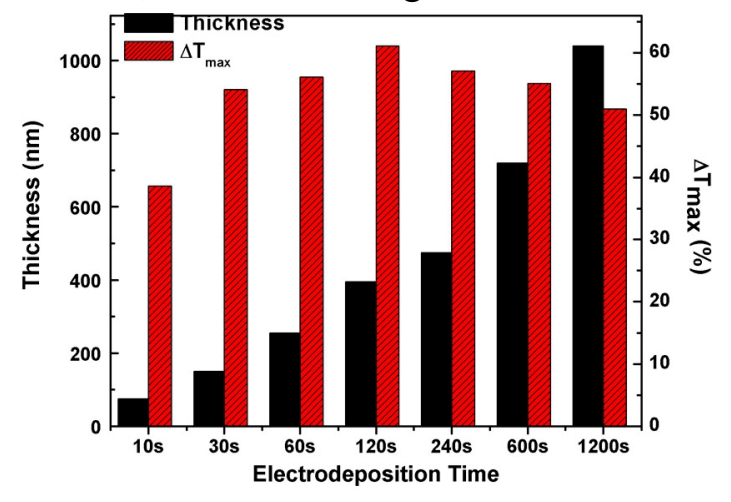

Fig. 1 The effect of deposition time on the thickness and $\Delta T_{\max }$ of Mo doped $\mathrm{V}_{2} \mathrm{O}_{5}$ film

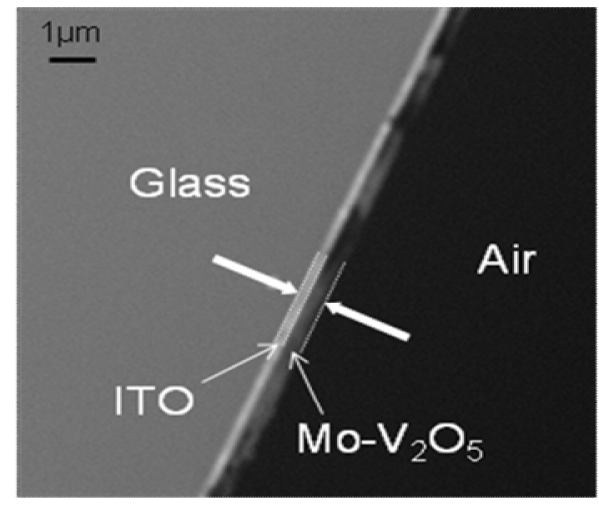

Fig. 2 SEM cross-sectional image of Mo doped $\mathrm{V}_{2} \mathrm{O}_{5}$ film with deposition time of $120 \mathrm{~s}$

During the process of electrochromism, the film switches from a transmissive, orange red color when oxidized $(+1.0 \mathrm{~V})$, to a dark green color $(+0.3 \mathrm{~V})$, a deeply absorptive purple/blue color when reduced $(-0.3$ and $-1.0 \mathrm{~V})$, which is in agreement with the blue shift of the corresponding absorbance peaks in the transmittance spectra. The electrochromism of Mo doped $\mathrm{V}_{2} \mathrm{O}_{5}$ film can be considered as a reversible reduction/oxidation process accompanying the double insertion/extraction of $\mathrm{Li}^{+}$ions and electrons. For as-deposited films, as the thickness of the film increases, the absorption edge has obvious red shift, and the optical band gap becomes narrow. This is attributed to the increase in absorbance for thicker films due to large number of atoms available for the absorption of photon energy [8]. For colored films, Mo doped $\mathrm{V}_{2} \mathrm{O}_{5}$ films showed increasing the coloring state with increasing the thickness of thin films. For the thin film of $90 \mathrm{~nm}$ thickness, the transmittance in the short wave $(<500 \mathrm{~nm})$ increased by more than $70 \%$, but the transmittance changes in the visible infrared wave $(>500 \mathrm{~nm})$ were about $60 \%$. For the thick film of $1050 \mathrm{~nm}$ thickness, the transmittance in the short wave $(<500 \mathrm{~nm})$ increased by $30 \%$, but the transmittance changes in the visible infrared wave $(>500 \mathrm{~nm})$ were about $50 \%$. 

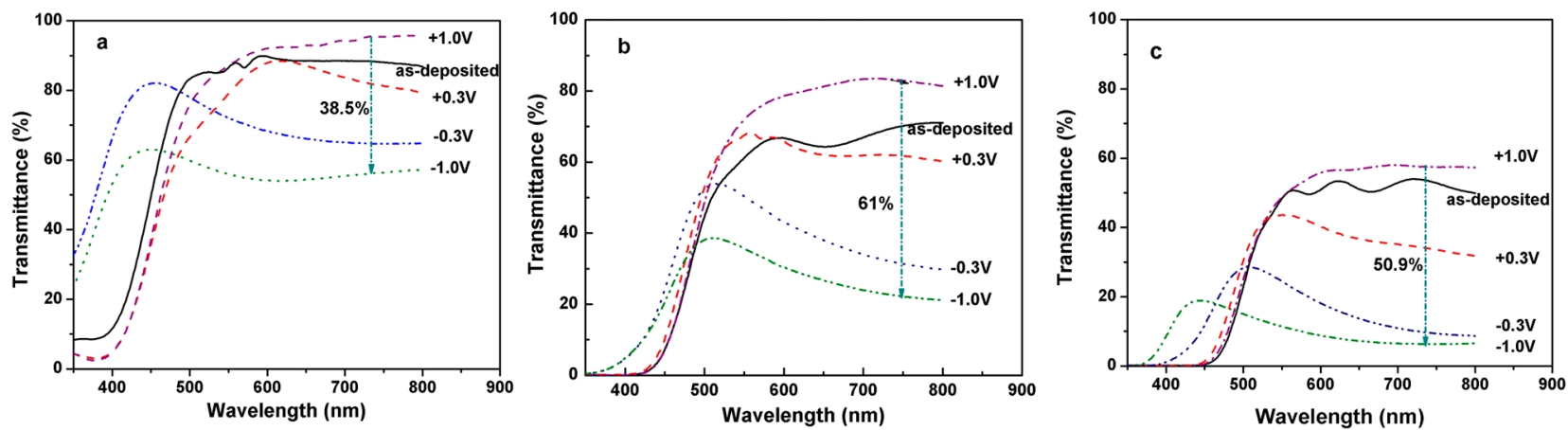

Fig. 3. Transmittance spectra of Mo doped $\mathrm{V}_{2} \mathrm{O}_{5}$ films with different electrodeposition time in different coloration states (a) $10 \mathrm{~s}$, (b) $120 \mathrm{~s}$, (c)1200 s. All films were polarized with the potential of $+1.0,+0.3,-0.3$ and $-1.0 \mathrm{~V}$, respectively, with an interval of $30 \mathrm{~s}$ in propylene carbonate solution containing $0.5 \mathrm{M} \mathrm{LiClO}_{4}$.

Effect of sol concentration on film thickness and electrochromic property. Fig. 4 shows the effect of sol concentration on film thickness and $\Delta T_{\max }$ with a specific deposition time of $100 \mathrm{~s}$. Fig. 6 shows the corresponding ex-situ optical transmittance data for Mo doped $\mathrm{V}_{2} \mathrm{O}_{5}$ films with different sol concentration $(0.0125,0.05$ and $0.1 \mathrm{M})$ in different coloration states, which the film was polarized at $+1.0,+0.3,-0.3$, and $-1.0 \mathrm{~V}$, respectively. As can be seen, with the extension of the sol concentration (from $0.0125 \mathrm{M} \mathrm{s}$ to $0.1 \mathrm{M}$ ), the thickness of the films increases sharply (from about $100 \mathrm{~nm}$ to 1500 $\mathrm{nm}$ ). Moreover, $\Delta T_{\max }$ for the film with different sol concentration is $36-62 \%$ in the spectral region $550-800 \mathrm{~nm}$, while $\Delta T_{\max }$ reach a maximum value of $61.6 \%$ at the sol concentration of $0.05 \mathrm{M}$ with the film thickness of about $400 \mathrm{~nm}$, as shown in Fig. 5.

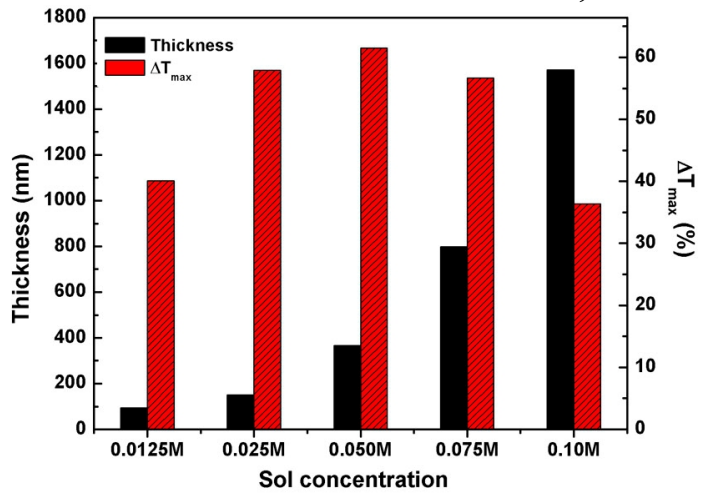

Fig.4 The effect of sol concentration on the thickness and $\Delta T_{\max }$ of Mo doped $\mathrm{V}_{2} \mathrm{O}_{5}$ film

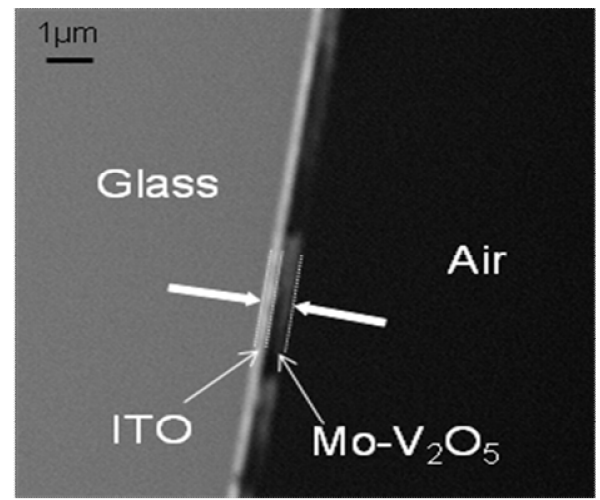

Fig. 5 SEM cross-sectional image of Mo doped $\mathrm{V}_{2} \mathrm{O}_{5}$ film electrodeposited with sol concentration of $0.05 \mathrm{M}$
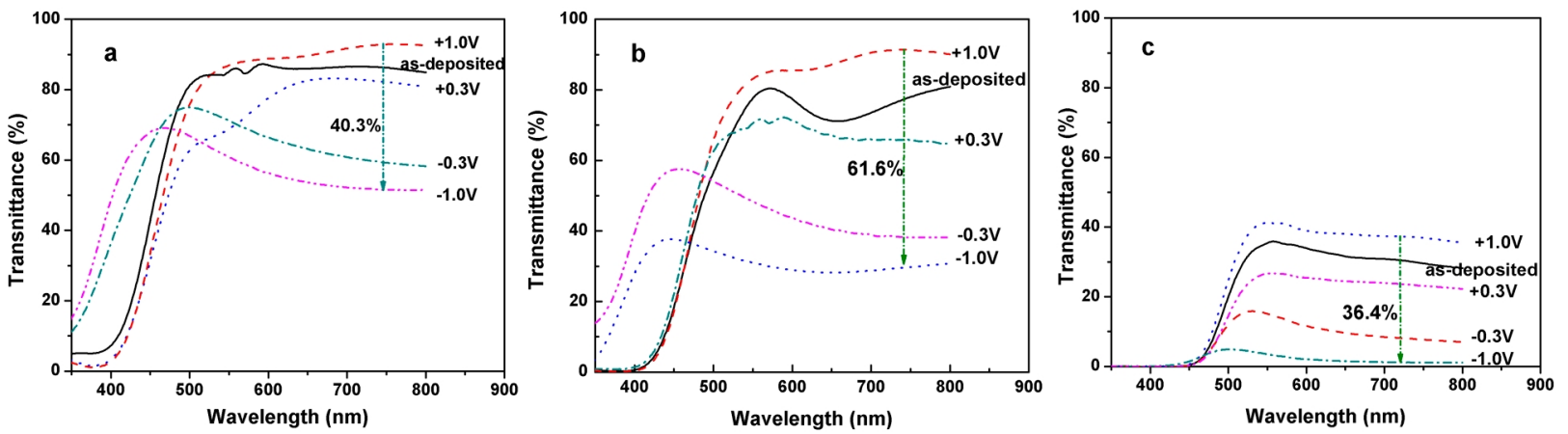

Fig. 6. Transmittance spectra of Mo doped $\mathrm{V}_{2} \mathrm{O}_{5}$ films with different sol concentration in different coloration states (a) $0.0125 \mathrm{M}$, (b) $0.05 \mathrm{M}$, (c) $0.1 \mathrm{M}$. All films were polarized with the potential of $+1.0,+0.3,-0.3$ and $-1.0 \mathrm{~V}$, respectively, with an interval of $30 \mathrm{~s}$ in propylene carbonate solution containing $0.5 \mathrm{M} \mathrm{LiClO}_{4}$. 
In order to verify the influence of sol concentration on film thickness, the particle size distribution and median particle size of Mo doped $\mathrm{V}_{2} \mathrm{O}_{5}$ sol at different molar concentration of $0.0125,0.025$, $0.05,0.075$ and $0.1 \mathrm{M}$ was investigated as shown in Fig. 7 . It can be found that the sol particle size decreases with the increase of the sol concentration. According to the theory of Stern's model, when the sol concentration is increased, the concentration of counter-ions in the medium is increased and then the diffusion layer is compressed and thinned, so the sol particle size decreases. The micelles with smaller particle size have a faster migration rate, so the thickness of the film deposited by a larger concentration of the sol is thicker at the same deposition time, which is consistant with the results of Fig.4.
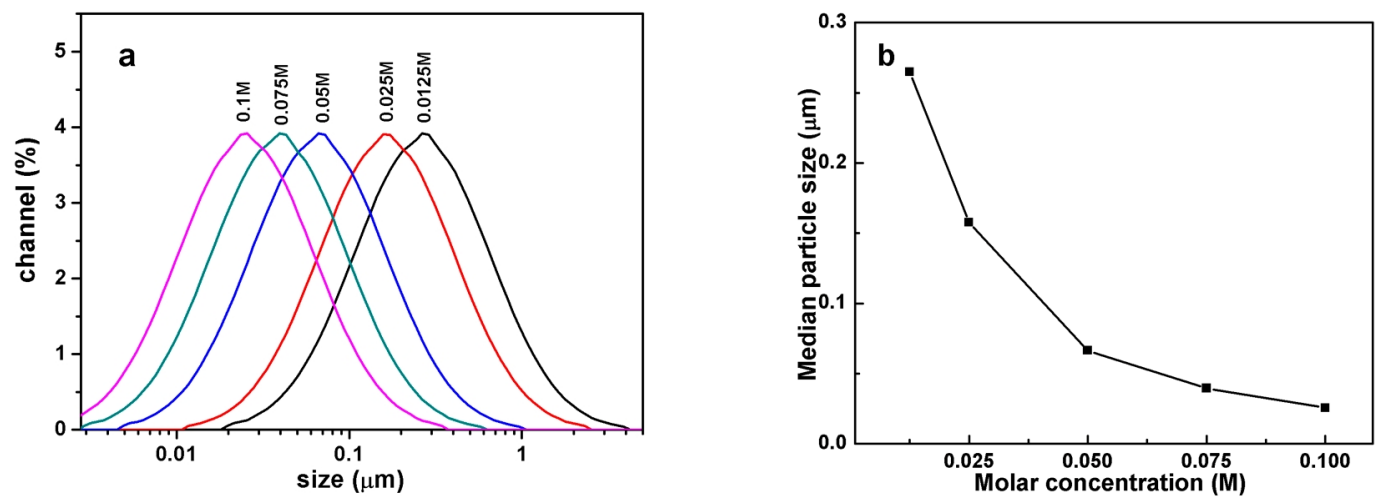

Fig.7. Particle size distribution (a) and median particle size (b) of different concentration Mo doped $\mathrm{V}_{2} \mathrm{O}_{5}$ sol

\section{Conclusions}

Mo doped $\mathrm{V}_{2} \mathrm{O}_{5}$ films were fabricated by cathodic electrodeposition. The deposition time and concentration of sol have been found to influence directly the optical modulation capability. With the increase of the electrodeposition time, the thickness of the films increases gradually. The thickness of the films increases sharply with the increase of the concentration of the sol. The best film with the thickness about $400 \mathrm{~nm}$ exhibited wide optical modulation over $60 \%$. The wide optical modulation of Mo doped $\mathrm{V}_{2} \mathrm{O}_{5}$ films render them to be a promising application in electrochromic devices.

\section{Acknowledgements}

This work was financially supported by the National Natural Science Foundation of China (51102187).

\section{References}

[1] T.J. Richardson, Solid State Ionics 165 (2003) 305-308.

[2] M.G. Hutchins, N.S. Butta, A.J. Toppinga, J. Gallegob, P. Milnec, D. Jeffreyc, I.Brotherstonc, Electrochim. Acta 46 (2001) 1983-1988.

[3] M. Zinzi, Build. Environ. 41 (2006) 1262-1273.

[4] G. Niklasson, C. Granqvist, J. Mater. Chem. 17 (2007) 127-156.

[5] A. Talledo, C.G. Granqvist, J. Appl. Phys. 77 (1995) 4655-4666.

[6] A.P. Jin, W. Chen, Q.Y. Zhu, Adv. Mater. Res. 79-82 (2009) 799-802.

[7] A.P. Jin, W. Chen, Q.Y. Zhu, Z.L. Jian, Electrochimi. Acta 55 (2010) 6408-6414.

[8] D.S. Dalavi, M.J. Suryavanshi, D.S. Patil, S.S. Mali, A.V. Moholkar, S.S. Kalagi, S.A. Vanalkar, S.R. Kang, J.H. Kim, P.S. Patil, Appl. Surf. Sci. 257 (2011) 2647 - 2656. 